\title{
The leucotriene receptor antagonist montelukast and the risk of Churg-Strauss syndrome: a case- crossover study
}

\author{
T Hauser, ${ }^{1,2}$ A Mahr, ${ }^{1,3}$ C Metzler, ${ }^{4}$ J Coste, ${ }^{3}$ R Sommerstein, ${ }^{2}$ W L Gross, ${ }^{4}$ L Guillevin, ${ }^{1}$ \\ B Hellmich ${ }^{4}$
}

${ }^{1}$ Department of Internal Medicine, for the French Vasculitis Study Group (FVSG). Hôpital Cochin, Université Paris 5 , Paris, France; ${ }^{2}$ Division of Clinical Immunology,

Department of Internal Medicine, University Hospital, Zurich, Switzerland:

${ }^{3}$ Department of Biostatistics, Hôpital Cochin, Université Paris 5, Paris, France; ${ }^{4}$ Rheumaklinik Bad Bramstedt,

Universitätsklinikum SchleswigHolstein, Lübeck, Germany

Correspondence to:

Dr A Mahr, Department of Internal Medicine, Hôpital Cochin, 27 rue du Faubourg Saint-Jacques, 75679 Paris Cedex 14, France; alfred.mahr@ cch.aphp.fr

$\mathrm{TH}$ and $\mathrm{AM}$ contributed equally to this work.

Received 29 July 2007 Accepted 27 January 2008 Published Online First 13 February 2008

\begin{abstract}
Background: There has been some concern that leucotriene receptor antagonists might precipitate the onset of Churg-Strauss syndrome (CSS). A study was undertaken to investigate the relationship between the leucotriene receptor antagonist montelukast and the onset of CSS.
\end{abstract}

Methods: Medication histories of 78 patients with CSS from France and Germany were retraced by questioning the patients, treating physicians and dispensing pharmacists, and from medical records. Using a case-crossover research design, exposures to montelukast and other asthma medications during the 3-month "index" period immediately preceding the onset of CSS were compared with those of four previous 3-month "control" periods. Odds ratios (ORs) were computed by conditional logistic regression.

Results: The ORs for CSS onset were 4.5 (95\% Cl 1.5 to 13.9) for montelukast, 3.0 (95\% Cl 0.8 to 10.5$)$ for inhaled long-acting $\beta_{2}$ agonists, 1.7 (95\% Cl 0.5 to 5.4 ) for inhaled corticosteroids and $4.0(95 \% \mathrm{Cl} 1.3$ to 12.5$)$ for oral corticosteroids. Montelukast exposure during control periods increased temporally over three consecutive calendar periods of CSS onset from 1999 to 2003 ( $p_{\text {trend }}$ $<0.0001$ ).

Conclusion: Montelukast use was associated with a 4.5fold higher risk of CSS onset within 3 months. However, the positive estimates obtained for other long-term asthma control medications suggest that this link might be confounded by a general escalation of asthma therapy before CSS onset. The association between montelukast and CSS observed in this study is probably also explained by the increasing use of this medication over time.

Churg-Strauss syndrome (CSS) is a small vessel vasculitis that occurs in the context of asthma and eosinophilia. The aetiology of this rare and potentially life-threatening disease is unknown. ${ }^{12}$ Over the last decade ${ }^{3-6}$ more than 100 cases of CSS, published or registered in post-marketing monitoring systems, have occurred in individuals receiving asthma treatment with a leucotriene receptor antagonist (LTRA; montelukast, zafirlukast or pranlukast). ${ }^{78}$ These reports have raised public health concerns that LTRA might precipitate the onset of CSS, even more so since the possibility of CSS being triggered or caused by drugs had been suspected previously. ${ }^{12}$

It was thought that LTRA could induce CSS via drug hypersusceptibility ${ }^{9}$ or a collateral effect of these agents on eosinophil chemoattraction. ${ }^{10}$ Based on clinical observations, the most widely favoured hypothesis put forward so far to explain the potential link between LTRA and CSS stipulated that LTRA administration allows tapering of corticosteroids needed to treat the asthma, thereby coincidentally unmasking a latent form of CSS. ${ }^{6}$ However, that theory conflicted with reports of LTRA-associated CSS occurring in the absence of concomitant corticosteroid reduction, ${ }^{311-15}$ the overall modest corticosteroid-sparing effect of LTRA $^{16}$ and the few similar observations made for drugs more potent at reducing oral corticosteroid doses such as inhaled corticosteroids. ${ }^{17-21}$ Most importantly, only rare observational studies sought to determine whether a real association exists between LTRA and CSS. ${ }^{22}$

We conducted a case-crossover study, a research design in which the cases act as their own controls, to explore the possible relationship between exposure to montelukast, the only LTRA available in the study area, and the development of CSS.

\section{METHODS}

\section{Study population}

Study participants were retrospectively recruited from the French Vasculitis Study Group (FVSG) and the Interdisciplinary Vasculitis Center, Bad Bramstedt, Germany. Candidates participating in the study from France were identified from patients enrolled in a prospective clinical trial conducted by the FVSG from 1995 to 2005. That trial evaluated therapeutic strategies for newly diagnosed CSS and included 140 patients from 55 French centres and a few other European medical centres; ${ }^{23}{ }^{24}$ for legal reasons, only patients enrolled in that trial by French centres were considered for this study. The Interdisciplinary Vasculitis Center Bad Bramstedt, a specialised tertiary referral centre, identified potential participants for the study from a prospective registry of all patients with vasculitis followed in their facility since 1991.

Montelukast was first approved in both countries in March/April 1998. ${ }^{25}{ }^{26}$ Because the study assessed exposures during the 15 -month period preceding the onset of CSS (see below), the databases for all individuals diagnosed with CSS between July 1999 and the time this study was launched in April 2004 were searched. Individuals for whom the investigation revealed that the onset of CSS predated July 1999 were subsequently excluded from the analyses. The final analysis also retained only subjects meeting the American College of Rheumatology (ACR) classification criteria $^{27}$ or those proposed by Lanham et $a^{28}$ (box 


\section{Box 1 Classification criteria for Churg-Strauss syndrome}

- Criteria of the American College of Rheumatology ${ }^{27}(\geqslant 4$ of 6 items required)

- Asthma

- Eosinophilia $>10 \%$ (on differential white blood cell count)

- Mono- or polyneuropathy

- Non-fixed pulmonary infiltrates

- Paranasal sinus abnormality

- Extravascular eosinophils on biopsy

- Criteria of Lanham et $a^{28}$ (all 3 items required)

- Asthma

- Peak peripheral blood eosinophil count $>1500 / \mathrm{mm}^{3}$

- Systemic vasculitis involving $\geqslant 2$ extrapulmonary organs

1). To avoid the possibility of incomplete data, we considered that the ACR criterion of "eosinophilia $>10 \%$ " was also met by an absolute peripheral eosinophil count $>1500 / \mathrm{mm}^{3}$.

\section{Data collection}

The time of onset of CSS and prior exposure to asthma treatments relevant to this study were examined using three information sources: (1) study participants, (2) their local treating physicians and hospital medical records, and (3) their pharmacists. We recorded exposures for the following four classes of long-term asthma control medications (with respective active principles): LTRA (montelukast), inhaled long-acting $\beta_{2}$ agonists (formoterol, salmeterol), inhaled corticosteroids (beclomethasone, budenoside, fluticasone) and oral corticosteroids (betamethasone, dexamethasone, methylprednisolone, prednisolone, prednisone). Furthermore, information on immunotherapy prescribed for allergies and vaccinations was collected to identify a potential confounding effect of these putative triggers of CSS. ${ }^{29}$ Throughout the investigation participants, their physicians and pharmacists were informed that the purpose of the study was to examine risk determinants of CSS without revealing its specific focus on montelukast.

\section{Interviews with study participants}

All study participants underwent a 40-60 min telephone interview using a detailed standardised questionnaire. Participants received the questionnaire beforehand to prepare for the interviews. To facilitate recall of previously used medications, the 8- and 10-page questionnaires listed by brand name the 36 and 62 medications (grouped in drug classes and sorted alphabetically) which are commonly available for asthma treatment in France and Germany, respectively. The questionnaires also included labelled colour photographs showing pharmaceutical formulations and devices with original packages of all listed medications. In France and Germany, drugs are delivered exclusively in their original distinctive packages as provided by the manufacturers. In addition, patients were encouraged to track down duplicates of their doctor's prescriptions they may have kept.

During the interviews we recorded the histories of asthma, sinusitis and allergy, and detailed information on the initial symptoms, date of onset of CSS and all subsequent manifestations until its diagnosis. Based on the list of medications provided in the questionnaires, the patients were then asked to name all the anti-asthmatic medications taken during the 2-year period prior to onset of CSS. Periods of exposures were recorded as months and years of initiation and withdrawal. Finally we asked for the identity and contact information of local treating physicians - mainly general practitioners, pulmonologists, allergists and otorhinolaryngologists-and the dispensing pharmacists they had consulted during the 2 -year period of interest. In addition to the information given orally during the interviews, the patients also returned the completed questionnaires by mail.

\section{Survey among treating physicians and review of medical records}

For each participant we attempted to contact his/her general practitioner and, when applicable, at least one local treating specialist able to provide reliable information regarding the use of asthma treatments. Treating physicians were either asked to reply by mail (Germany) or questioned by telephone (France); in the latter case, the investigator making the telephone call was unaware of the information collected during patients' interviews. The physicians were asked for detailed information on initial CSS manifestations and all anti-asthmatic treatments prescribed during a period from 2 years before the onset of CSS until its diagnosis, based on the dates initially provided by the patients during the telephone interviews.

Hospital medical records-including trial report forms and/or hospital discharge letters-were reviewed with respect to date and signs of onset of CSS and drug histories.

\section{Survey among dispensing pharmacists}

All pharmacists indicated by the participants were asked by mail to provide us with printouts of electronic records on any medications they had dispensed to those clients during the entire period under investigation, as defined above. In France and Germany, drug deliveries are limited to a 30-day maximum supply and therefore patients receiving long-term medications must return to the pharmacy every month.

\section{Definition of CSS onset and prior exposures}

We then collated all the collected information to define each patient's date of CSS onset, which was defined as the very first occurrence of any manifestations attributable to CSS. Symptoms attributed to asthma, sinusitis and/or allergic conditions and exposures to medications were not considered to determine CSS onset. Unless a precise day or week of onset could be cited, the date was set at the 15th day of the respective month.

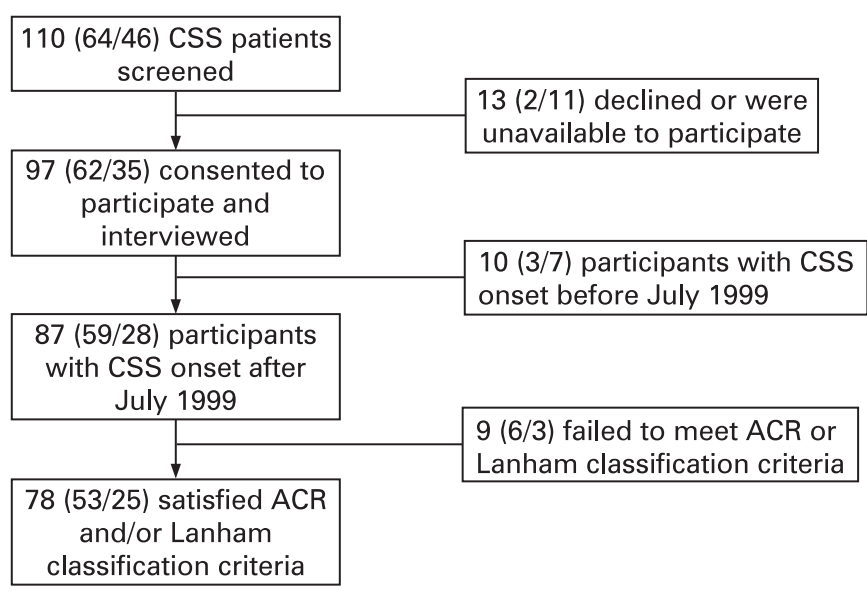

Figure 1 Flow chart of the study population (numbers in parentheses refer to patients with Churg-Strauss syndrome (CSS) identified from the French Vasculitis Study Group and the Interdisciplinary Vasculitis Center, Bad Bramstedt, respectively). ACR, American College of Rheumatology. 
Table 1 Characteristics of the 78 study subjects at time of diagnosis of Churg-Strauss syndrome (CSS)

\begin{tabular}{|c|c|c|c|}
\hline \multirow[b]{2}{*}{ Criteria } & \multirow[b]{2}{*}{ All } & \multicolumn{2}{|c|}{ Exposure to montelukast } \\
\hline & & Yes & No \\
\hline Subjects (n) & 78 & 20 & 58 \\
\hline Mean (SD) age (years) & $53.9(13.8)$ & $51.3(13.0)$ & $54.8(13.9)$ \\
\hline $\operatorname{Sex}(M / F), n$ & $43 / 35$ & $9 / 11$ & $34 / 24$ \\
\hline Prior asthma, $\mathrm{n}(\%)$ & $76 / 78(97)$ & $20 / 20(100)$ & $56 / 58(97)$ \\
\hline \multicolumn{4}{|l|}{ Disease presentation, $\mathrm{n}(\%)$} \\
\hline Polyposis & 48/77 (62) & $13 / 20(65)$ & $35 / 57(61)$ \\
\hline Sinusitis & $67 / 78(86)$ & $19 / 20(95)$ & $48 / 58(83)$ \\
\hline Pulmonary infiltrate & $49 / 78(63)$ & $12 / 20(60)$ & $37 / 58(64)$ \\
\hline Eosinophilic alveolitis & $28 / 77(36)$ & $7 / 20(35)$ & $21 / 57$ (37) \\
\hline Alveolar haemorrhage & $3 / 78(4)$ & $1 / 20(5)$ & $2 / 58(3)$ \\
\hline Peripheral nerve involvement & $50 / 78(64)$ & $13 / 20(65)$ & $37 / 58(64)$ \\
\hline Cardiac involvement & $30 / 78(38)$ & $6 / 20(30)$ & $24 / 58(41)$ \\
\hline Cutaneous involvement & $26 / 78(33)$ & $7 / 20(35)$ & $19 / 58(33)$ \\
\hline Arthritis & $12 / 78(15)$ & $3 / 20(15)$ & $9 / 58(16)$ \\
\hline Glomerulonephritis & $8 / 78(10)$ & $3 / 20(15)$ & $5 / 58(9)$ \\
\hline ANCA positivity, n (\%) & $30 / 74(41)$ & $6 / 19(32)$ & $24 / 55(44)$ \\
\hline C-ANCA or anti-PR3* & 6/74 (8) & 0 & $6 / 55(11)$ \\
\hline Anti-MPO* & $20 / 74(27)$ & $5 / 19(26)$ & $15 / 55(27)$ \\
\hline Histological proof, n (\%) & $45 / 78(58)$ & $11 / 20(55)$ & $34 / 58(59)$ \\
\hline Peripheral eosinophilia†, n (\%) & $72 / 78(92)$ & $18 / 20(90)$ & $54 / 58(93)$ \\
\hline \multicolumn{4}{|c|}{ Classification criteria satisfied, $\mathrm{n}(\%)$} \\
\hline ACR & $75 / 78$ (96) & $19 / 20(95)$ & $56 / 58$ (97) \\
\hline Lanham & $44 / 78$ (56) & $12 / 20(60)$ & $32 / 58$ (55) \\
\hline Both & $41 / 78(53)$ & $11 / 20(55)$ & $30 / 58(52)$ \\
\hline
\end{tabular}

Using this date, we then established the individual exposure histories for the 15-month period preceding the onset of CSS. Exposure times to drugs of the same pharmacological category were cumulated; for inhaled combination therapies with longacting $\beta_{2}$ agonists and corticosteroids, exposures were assigned to both classes. The precise beginning and end of exposure were primarily determined using information given by the treating physicians and/or pharmacists; when unavailable, exposure periods were defined using the dates mentioned by the patient and/or hospital records.

\section{Case-crossover analysis}

The risk of CSS onset associated with the investigated drug classes was assessed by a case-crossover analysis. ${ }^{30}$ This variant of a traditional case-control study compares exposures to a potential risk factor during the "index" period immediately preceding the event (eg, disease onset) with those during several prior "control" periods. Based on putative pathogenic mechanisms, ${ }^{91}$ we considered for our primary analysis that the onset of CSS would occur within 3 months of the first exposure to montelukast or another pharmaceutical trigger. Accordingly, for each patient, the four consecutive 3 -month periods immediately preceding the 3-month index period served as control periods. An index or control effect period was defined as being exposed to a medication class as soon as a drug belonging to that class had been used for at least 1 day during the period. When the period of use for a given medication class could not be precisely determined, the corresponding effect periods were treated as

Table 2 Exposure rates for montelukast and other anti-asthmatic drugs during the 15 months preceding the onset of Churg-Strauss syndrome (CSS): total and individual 3-month effect periods and stratified for the year of CSS onset

\begin{tabular}{|c|c|c|c|c|c|c|c|c|}
\hline & $\begin{array}{l}\text { Montelukast } \\
\text { N/total (\%) }\end{array}$ & $\mathbf{p}_{\text {trend }}$ & $\begin{array}{l}\text { LABA } \\
\text { N/total }(\%)\end{array}$ & $\mathbf{p}_{\text {trend }}$ & $\begin{array}{l}\text { Inhaled CS } \\
\text { N/total (\%) }\end{array}$ & $\mathbf{p}_{\text {trend }}$ & $\begin{array}{l}\text { Oral CS } \\
\text { N/total (\%) }\end{array}$ & $\mathbf{p}_{\text {trend }}$ \\
\hline Total & $20 / 78(26)$ & & $51 / 78(65)$ & & $57 / 78(73)$ & & $43 / 78(55)$ & \\
\hline Control $4(-12 /-15$ months before onset) & $6 / 78(8)$ & & $37 / 72(51)$ & & $46 / 74(62)$ & & $28 / 73(38)$ & \\
\hline Control $3(-9 /-12$ months before onset) & $8 / 78(10)$ & & $40 / 71(56)$ & & $46 / 74(62)$ & & $29 / 72(40)$ & \\
\hline Control $2(-6 /-9$ months before onset) & $9 / 78(12)$ & .13 & $42 / 71(59)$ & 0.09 & $48 / 74(65)$ & & $31 / 72(43)$ & \\
\hline Control $1(-3 /-6$ months before onset) & $12 / 78(15)$ & & $47 / 72(65)$ & & $50 / 74(68)$ & & $33 / 72(46)$ & \\
\hline Index ( $0 /-3$ months before onset) & $15 / 78(19)$ & & $45 / 71(63)$ & & $49 / 73(67)$ & & $35 / 70(50)$ & \\
\hline \multicolumn{9}{|l|}{ Control exposure according to year of CSS onset } \\
\hline $1999 / 2000$ & $1 / 112(1)$ & & $60 / 105(57)$ & & $65 / 112(58)$ & & 48/108 (44) & \\
\hline 2001 & 10/88 (11) & $<0.0001$ & 45/81 (56) & 0.58 & $54 / 80(68)$ & 0.11 & $39 / 84(46)$ & 0.18 \\
\hline $2002 / 3$ & $24 / 112(21)$ & & $61 / 100(61)$ & & $71 / 104(68)$ & & $34 / 97$ (35) & \\
\hline
\end{tabular}

CS, corticosteroids; LABA, inhaled long-acting $\beta_{2}$ agonists.

$\mathrm{N} /$ total, numbers of periods exposed/total periods. 
missing data. In addition, sensitivity analyses-using 2-month (one index and six control periods) and 4-month effect periods (one index and two control periods) - and subgroup analyses were performed to test for the robustness of the results of the primary analysis. The assumption that there is no linear trend in the probability of exposure to each of the medication classes considered over time was verified by first comparing the levels of exposure across the four control periods preceding the onset of CSS and then by comparing the pooled levels of exposure during four control periods analysed by year of CSS onset.

\section{Statistical analyses}

For the case-crossover analysis, conditional logistic regression was used to estimate matched odds ratios (ORs). ${ }^{32}$ Categorical variables were compared using a $\chi^{2}$ test and, when appropriate, Fisher exact tests, and continuous variables were compared with the Student $t$ test or Kruskal-Wallis test. For all statistical analyses a two-tailed $p$ value $<0.05$ was considered significant.

\section{RESULTS}

\section{Patient selection and responses to surveys}

From a total of 110 screened files, 78 patients (71\%) were identified who fulfilled all selection criteria and consented to participate in the study (fig 1).

Information from at least one community physician was obtained for 71 participants (91\%). Printouts of the medications dispensed by pharmacists covering the entire 15-month period investigated were obtained for 40 participants (51\%) and covering part of this period for $11(14 \%)$. No information was obtained from either treating physicians or dispensing pharmacists for three patients (4\%).

\section{Clinical data}

The main characteristics of the 78 subjects are listed in table 1. Most of the patients (96\%) satisfied ACR classification criteria for CSS; only three (4\%) were included based solely on Lanham's criteria. In addition, all but one subject fulfilled at least one of the following items: (1) histological proof of vasculitis, granulomatosis and/or extravascular eosinophilia;

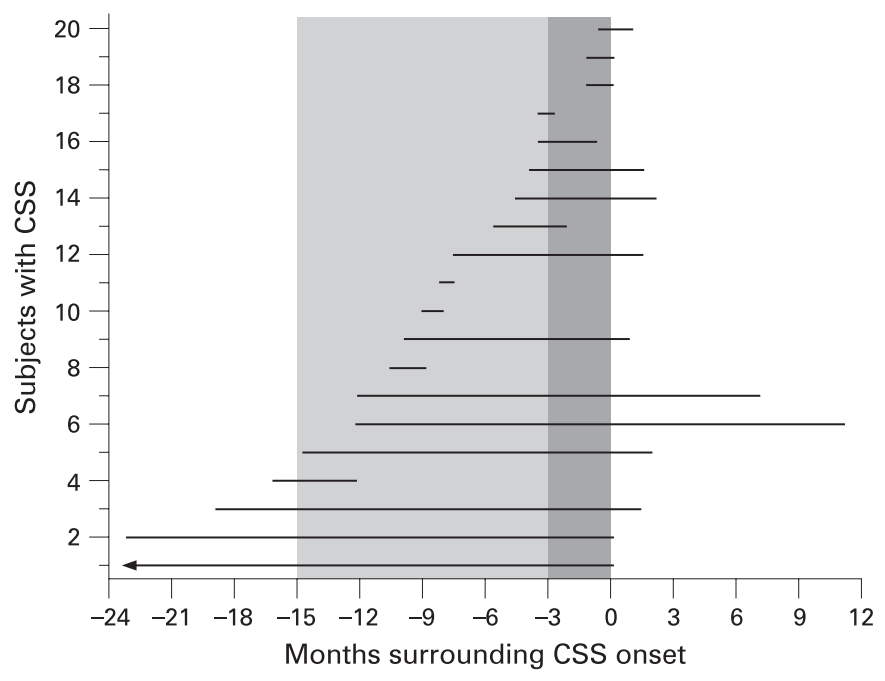

Figure 2 Timing of montelukast use for 20/78 subjects during the 15 months preceding the onset of Churg-Strauss syndrome (CSS). Horizontal bars represent the exposure period plotted versus the CSS onset date (month 0), the 3-month "index" period (dark grey) and the 3month "control" periods (light grey).
(2) positive antineutrophil cytoplasm antibody (ANCA) testing; (3) peripheral eosinophilia $>1500 / \mathrm{mm}^{3}$ and/or $>10 \%$ of the white blood cell count.

The mean (SD) time between onset of CSS and diagnosis was 3.8 (4.0) months (median 2.4). Among the 76 individuals (97\%) with prior asthma, the mean (SD) interval between onset of asthma and onset of CSS was 92.8 (120.3) months (median 42.8). Seventeen individuals (22\%) developed asthma $<15$ months before the onset of CSS.

\section{Drug exposures}

Table 2 shows the exposure rates to montelukast and the other investigated classes of asthma medications during the 15 months before CSS onset, either as total or stratified by 3month index and control periods. Overall, the mean (SD) number of these anti-asthmatic drug classes used was 2.2 (1.3) (median 2.5). Exposure rates to all four asthma medication classes increased from the earliest to the latest control periods, although not in a statistically significant manner (table 2).

To investigate whether there was a secular trend in drug intake, the pooled exposure frequencies were compared during control periods stratified by time tertiles of CSS onset (July 1999-December 2000, January-December 2001 and January 2002-December 2003). This analysis showed a statistically significant increase in exposure to montelukast over time $(\mathrm{p}<0.0001$, table 2$)$.

Twenty individuals (26\%) were exposed to montelukast during the 15 months before CSS onset. For 16 (80\%) of them, information on montelukast intake was obtained from at least two sources. The mean (SD) interval from starting of montelukast to CSS onset was 11.3 (13.8) months (median 8.4); the individual durations of montelukast intake against time of CSS onset are shown in fig 2. Pertinently, 7 of these 20 individuals were not taking oral corticosteroids during the 3 month period of montelukast initiation. In addition, 7 other individuals (9\%) were identified who received montelukast only before the 15 -month period under study $(n=3)$ or after the onset of CSS $(n=4)$.

Comparisons of baseline characteristics such as organ manifestations of CSS and ANCA positivity did not reveal any statistically significant differences between patients exposed to montelukast and those not exposed to the drug during the 15 months preceding the onset of CSS (table 1).

During the 3-month index period, immunotherapy against allergies was identified in two patients and flu vaccinations in three others; none of these five patients had been exposed to montelukast. Immunotherapy had been started $>2$ years before CSS onset.

\section{Case-crossover analysis}

Results of the case-crossover analysis are reported in table 3. In the primary analysis, exposure to montelukast and CSS onset within 3 months yielded an OR of 4.5 (95\% confidence interval (CI) 1.5 to 13.9). Positive ORs were also obtained for the other investigated classes of anti-asthmatic drugs and, in the sensitivity analyses, for 2- or 4-month index and control periods (table 3). In a multivariate model including all four asthma medication classes as covariates, the ORs for 3-month periods were 6.7 (95\% CI 1.3 to 34.1) for montelukast, 2.9 (95\% CI 0.6 to 13.3 ) for inhaled long-acting $\beta_{2}$ agonists, 1.0 (95\% CI 0.2 to 4.8) for inhaled corticosteroids and 4.2 (95\% CI 1.2 to 14.6) for oral corticosteroids. 
Table 3 Risk of Churg-Strauss syndrome associated with exposure to montelukast or other anti-asthmatic agents (according to a case-crossover analysis) within the 3 months preceding onset of vasculitis (primary analysis) and 2- or 4-month risk periods (sensitivity analyses)

\begin{tabular}{|c|c|c|c|c|c|c|c|c|c|}
\hline \multirow[b]{3}{*}{ Drug category } & \multicolumn{3}{|c|}{ 3-month periods } & \multicolumn{3}{|c|}{ 2-month periods } & \multicolumn{3}{|c|}{ 4-month periods } \\
\hline & \multicolumn{2}{|c|}{ Periods exposed (\%) } & \multirow[b]{2}{*}{ OR $(95 \% \mathrm{Cl})$} & \multicolumn{2}{|c|}{ Periods exposed (\%) } & \multirow[b]{2}{*}{ OR (95\% Cl) } & \multicolumn{2}{|c|}{ Periods exposed (\%) } & \multirow[b]{2}{*}{ OR (95\% Cl) } \\
\hline & Index & Controls & & Index & Controls & & Index & Controls & \\
\hline LABA & 63 & 57 & $3.0(0.8$ to 10.5$)$ & 64 & 58 & $4.1(1.0$ to 16.6$)$ & 66 & 62 & $3.6(0.7$ to 19.0$)$ \\
\hline Inhaled corticosteroids & 67 & 64 & $1.7(0.5$ to 5.4$)$ & 67 & 64 & $1.7(0.5$ to 5.7$)$ & 68 & 67 & $1.3(0.4$ to 4.9$)$ \\
\hline Oral corticosteroids & 50 & 42 & $4.0(1.3$ to 12.5$)$ & 50 & 42 & 8.6 (2.2 to 33.3 ) & 50 & 43 & $4.0(1.0$ to 15.6$)$ \\
\hline
\end{tabular}

LABA, inhaled long-acting $\beta_{2}$ agonists; $\mathrm{OR}$, odds ratio; $\mathrm{Cl}$, confidence interval.

To evaluate the effect of overall long-term increased exposure to montelukast with calendar year, we calculated the OR for montelukast for three periods of CSS onset, as defined above. This subgroup analysis yielded an infinite OR for the earliest period (July 1999-December 2000) and ORs of 2.2 (95\% CI 0.5 to 10.9$)$ and $2.3(95 \%$ CI 0.3 to 16.7$)$ for the two following periods (January-December 2001 and January 2002-December 2003), respectively. A further subgroup analysis restricted to the 59 subjects $(76 \%)$ with a history of asthma lasting at least 15 months yielded the following ORs for 3-month risk periods: montelukast 4.5 (95\% CI 1.5 to 13.7), long-acting $\beta_{2}$ agonists 3.7 (95\% CI 0.7 to 19.5 ), inhaled corticosteroids 0.3 (95\% CI 0.05 to 1.8) and oral corticosteroids 5.0 (95\% CI 1.4 to 17.4).

\section{DISCUSSION}

The results of this case-crossover analysis of 79 subjects with CSS indicate that treatment with montelukast is associated with a statistically significant 4.5-fold increased risk of developing CSS within 3 months. However, use of inhaled long-acting $\beta_{2}$ agonists and oral corticosteroids also incurred increased risk ratios of comparable strengths for developing CSS, although only the latter reached statistical significance. Consistent effect-size estimates were obtained by sensitivity analyses for varied effect-period lengths and for the subgroup of patients whose asthma had been diagnosed at least 15 months before CSS onset. Taken together, these findings might suggest that the association with the onset of CSS is not specific to montelukast but a phenomenon possibly associated with the group of medications prescribed for long-term control of severe asthma.

The case-crossover design, as implemented here, has become widely used in pharmacoepidemiology. ${ }^{33}$ This technique was initially devised to analyse the effect of transient exposures on acute events, but has also proved useful in the setting of prolonged exposures and events with more subtle onset. ${ }^{34} 35$ Because this method uses self-matching, it eliminates the risk of between-person confounding due to differences in unmeasured or unknown factors that might exist between cases and controls. However, because the case-crossover design implicitly assumes that the exposure to the risk factor under study is constant across control periods, bias could occur when there is a time trend for exposure. ${ }^{36}$

We think that the case-crossover design enabled a more adequate assessment of a possible LTRA-associated risk of developing CSS than a traditional case-control study, especially because it avoided the difficult task of selecting a valid control group. As demonstrated by the high exposure to inhaled longacting $\beta_{2}$ agonists $(65 \%)$, oral $(56 \%)$ and inhaled corticosteroids $(73 \%)$ within the 15 months prior to CSS onset, the asthma associated with CSS is typically severe ${ }^{12}$ and the fact that montelukast had been given to $26 \%$ of the subjects might also highlight this severity. A traditional case-control design would therefore run the risk of bias due to imperfect or absent matching of controls for the asthma phenotype or other unmeasured factors that may differ between patients with asthma who developed CSS and asthmatic controls. This possibility of inappropriate selection of controls hampers the interpretation of a previously conducted case-control study examining the potential impact of LTRA on CSS. ${ }^{22}$ Although that study also found an association between CSS and the use of LTRA and other anti-asthmatic medications, their results might be attributable to the likely milder asthma of controls who had been selected from a general asthma population.

Our results point to a different mechanism in the association between LTRA and CSS from that previously proposed. In light of the sustained and general escalation of asthma therapy prior to CSS onset (table 1), the most plausible explanation for linking montelukast to CSS appears to be confounding by indication due to gradually worsening asthma. Albeit poorly documented, this scenario fits the concept of a prodromal phase characterised by increasing frequency and severity of asthma attacks before vasculitis emerges as the hallmark of CSS. ${ }^{28} 3738$ Moreover, we confirmed previous observations ${ }^{79}$ that the time from montelukast initiation to CSS onset frequently lasted many months. This long interval is difficult to reconcile with the theories of a collateral drug effect such as eosinophil chemoattraction or corticosteroid tapering "unmasking" CSS or hypersusceptibility to montelukast, because such adverse events would be expected during the early phase of first exposure. ${ }^{39}$

Analysis of prescribing patterns for montelukast also provides insight into the observed association between this agent and CSS. In our study population exposure to montelukast rose markedly for CSS onsets from 1999 to 2003, a finding that certainly reflects the increased use of montelukast in clinical practice following its approval in 1998. Bearing in mind the vulnerability of the case-crossover design in a situation in which the probability of exposure is time-dependent, this long-term trend may have further contributed to the observed association between montelukast and CSS onset. Indeed, OR stratified by years of CSS onset indicated a more conservative twofold risk for the two most recent periods, supporting the suggestion that the overall estimate of 4.5 was inflated by the low prescription rates during the earliest phase after montelukast marketing authorisation. As for any new medication, this striking secular increase in montelukast use might also have distorted the general perception of the risk associated with it.

The present study has strengths and limitations. Knowing that CSS is a highly uncommon disorder with an annual incidence of 3 per million, ${ }^{2}$ its strengths include the large number of well characterised and a priori unselected individuals that accorded our analyses both generalisability of their results and reasonable statistical power. The potential of recall bias was 
minimised by meticulous retracing of drug histories of a variety of anti-asthmatic agents from several independent information sources. A possible limitation remains the difficulty in defining and determining the exact dates of CSS onset; however, nondifferential misclassification should have had a similar effect on the estimates for montelukast and the other drug classes investigated. It must also be kept in mind that the premise of our study was that CSS occurs within a definite time period after exposure to a pharmacological risk factor. Another shortcoming is that we focused only on montelukast as it is the only LTRA approved in France and Germany. We think that the interpretation of our data could also hold true for CSS development subsequent to zafirlukast and pranlukast exposure and also following treatment with other asthma or allergy medications. ${ }^{4}$ 17-21 40-42

In conclusion, the results of this study demonstrate a close relationship between montelukast intake and acute CSS onset. It is hypothesised that montelukast use is a proxy measure for gradually worsening asthma at an individual level and for the important increase in montelukast exposure in general.

Acknowledgements: The authors thank the following physicians of the FVSG who contributed to this study (in alphabetical order by city): R Cevallos (Amiens); N Tudesq (Bergérac); J P Battesti (Bobigny); J M Ragnaud (Bordeaux); A Levy (Bourges); M Roux (Bourgoin-Jallieu); P Letellier, Y Ollivier, A Zoulim (Caen); H Mouawad (Charleville-Mézières); V loos, F Parent (Clamart); B Pons (Clermont-Ferrand); V Rieu (Clermont-Ferrand); D Merrien (Compiègne); G Mangiapan (Créteil); F Lifermann (Dax); A Randrianjohanny (Freyming-Merlebach); X Mariette (Le Kremlin-Bicêtre); X Puéchal (Le Mans); G Khayat (Levallois-Perret); J de Sèze (Lille); M Lambert (Lille); J F Cordier, J S Martinon, J Ninet (Lyon); J F Dunand (Meaux); J Charbonneau (Montbéliard): $S$ Rivière (Montpellier); P Chevalet, M Hamidou (Nantes); J F Pouget-Aradie (Niort); E Aslangul, M Aubier, B Crestani, G Hayem, J Lacronique, C Le Jeunne (Paris); L Lequen (Pau); M Benichou (Pau); 0 Caubet, J F Viallard (Pessac); F Caron, C Landron (Poitiers); P Y Le Berruyer (Reims); P Delaval (Rennes); S Dominique (Rouen); E Briens (Saint-Brieuc); C Halimi (Senlis); E Diot (Tours); C Bergoin (Valenciennes). We are also indebted to $\mathrm{J}$ Jacobson for editorial assistance.

Funding: This study received a grant from the GIS-Institut des Maladies Rares, Paris, France. AM was supported in part by a Vasculitis Clinical Investigator Fellowship from the Vasculitis Clinical Research Consortium (VCRC) through a grant from the National Institutes of Health (National Center for Research Resources and the National Institute of Arthritis and Musculoskeletal and Skin Diseases) (NIH-NCRR: U54 RR019497).

Competing interests: None.

Ethics approval: The study protocol was reviewed and approved by the Commission Nationale de l'Informatique et des Libertés in France and the ethics committee of the University of Lübeck in Germany. All patients gave written informed consent to participate in the study.

\section{REFERENCES}

1. Conron M, Beynon HL. Churg-Strauss syndrome. Thorax 2000:55:870-7.

2. Noth I, Strek ME, Leff AR. Churg-Strauss syndrome. Lancet 2003;361:587-94.

3. Franco J, Artes MJ. Pulmonary eosinophilia associated with montelukast. Thorax 1999;54:558-60.

4. Josefson D. Asthma drug linked with Churg-Strauss syndrome. BMJ 1997:315:330

5. Kinoshita M, Shiraishi T, Koga T, et al. Churg-Strauss syndrome after corticosteroid withdrawal in an asthmatic patient treated with pranlukast. J Allergy Clin Immunol 1999:103:534-5.

6. Wechsler ME, Garpestad E, Flier SR, et al. Pulmonary infiltrates, eosinophilia, and cardiomyopathy following corticosteroid withdrawal in patients with asthma receiving zafirlukast. JAMA 1998;279:455-7.

7. Pagnoux C, Guilpain P, Hauser T, et al. Churg-Strauss syndrome and leukotrienemodifying agents. Clinical Pulmonary Medicine 2004;11:349-54.

8. Weller PF, Plaut M, Taggart V, et al. The relationship of asthma therapy and ChurgStrauss syndrome: NIH workshop summary report. J Allergy Clin Immunol 2001;108:175-83.

9. Stirling RG, Chung KF. Leukotriene antagonists and Churg-Strauss syndrome: the smoking gun. Thorax 1999:54:865-6.

10. Honsinger RW. Zafirlukast and Churg-Strauss syndrome (with discussion). JAMA 1998;279:1949-50.
11. Green RL, Vayonis AG. Churg-Strauss syndrome after zafirlukast in two patients not receiving systemic steroid treatment. Lancet 1999;353:725-6.

12. Katz RS, Papernik M. Zafirlukast and Churg-Strauss syndrome (with discussion). JAMA 1998;279:1949-50.

13. Knoell DL, Lucas J, Allen JN. Churg-Strauss syndrome associated with zafirlukast. Chest 1998;114:332-4.

14. Tuggey JM, Hosker HS. Churg-Strauss syndrome associated with montelukast therapy. Thorax 2000;55:805-6.

15. Villena V, Hidalgo R, Sotelo MT, et al. Montelukast and Churg-Strauss syndrome. Eur Respir J 2000;15:626.

16. Ducharme F, Schwartz Z, Hicks G, et al. Addition of anti-leukotriene agents to inhaled corticosteroids for chronic asthma. Cochrane Database Syst Rev 2004:CD003133.

17. Barnes NC. Clinical tolerability of zafirlukast, a new oral antileukotriene drug. Eur Respir Rev 1998;8:194-8.

18. Cooper SM, Libman BS, Lazarovich M. Churg-Strauss syndrome in a group of patients receiving fluticasone for asthma. J Rheumatol 2002;29:2651-2.

19. D'Cruz DP, Barnes NC, Lockwood CM. Difficult asthma or Churg-Strauss syndrome? BMJ 1999;318:475-6.

20. Le Gall C, Pham S, Vignes $S$, et al. Inhaled corticosteroids and Churg-Strauss syndrome: a report of five cases. Eur Respir J 2000;15:978-81.

21. Wechsler ME, Finn D, Gunawardena D, et al. Churg-Strauss syndrome in patients receiving montelukast as treatment for asthma. Chest 2000;117:708-13.

22. Harrold LR, Patterson MK, Andrade SE, et al. Asthma drug use and the development of Churg-Strauss syndrome. Pharmacoepidemiol Drug Saf 2007;16:620-6.

23. Cohen $\mathbf{P}$, Pagnoux $\mathrm{C}$, Mahr A, et al. Churg-Strauss syndrome with poor-prognosis factors: a prospective multicenter trial comparing glucocorticoids and 6 or 12 cyclophosphamide pulses in 48 patients. Arthritis Rheum 2007;57:686-93.

24. Ribi C, Cohen P, Pagnoux C, et al. Treatment of Churg-Strauss syndrome without poor-prognosis factors: a prospective study on 72 patients. Arthritis Rheum 2008:58:586-94.

25. Anon. Fachinformation Singulair. MSD/Dieckmann Arzneimittel GmbH. Stand Mai 2006.

26. Anon. Avis d'octroi d'autorisations de mise sur le marché de spécialités pharmaceutiques. Bulletin Officiel No 98-51. SP 22633215

27. Masi AT, Hunder GG, Lie JT, et al. The American College of Rheumatology 1990 criteria for the classification of Churg-Strauss syndrome (allergic granulomatosis and angiitis). Arthritis Rheum 1990;33:1094-100.

28. Lanham JG, Elkon KB, Pusey CD, et al. Systemic vasculitis with asthma and eosinophilia: a clinical approach to the Churg-Strauss syndrome. Medicine (Baltimore) 1984;63:65-81.

29. Guillevin L, Cohen P, Gayraud M, et al. Churg-Strauss syndrome. Clinical study and long-term follow-up of 96 patients. Medicine (Baltimore) 1999;78:26-37.

30. Maclure M. The case-crossover design: a method for studying transient effects on the risk of acute events. Am J Epidemiol 1991;133:144-53.

31. Hellmich B, Ehlers S, Csernok E, et al. Update on the pathogenesis of Churg-Strauss syndrome. Clin Exp Rheumatol 2003:21(Suppl 32):S69-77.

32. Mittleman MA, Maclure M, Robins JM. Control sampling strategies for casecrossover studies: an assessment of relative efficiency. Am J Epidemiol 1995:142:91-8.

33. Etminan M, Gill S, Fitzgerald $\mathbf{M}$, et al. Challenges and opportunities for pharmacoepidemiology in drug-therapy decision making. J Clin Pharmacol 2006; 46:6-9.

34. Viboud C, Boelle PY, Kelly J, et al. Comparison of the statistical efficiency of casecrossover and case-control designs: application to severe cutaneous adverse reactions. J Clin Epidemiol 2001;54:1218-27.

35. Wang PS, Schneeweiss S, Glynn RJ, et al. Use of the case-crossover design to study prolonged drug exposures and insidious outcomes. Ann Epidemiol 2004:14:296-303.

36. Greenland $\mathbf{S}$. Confounding and exposure trends in case-crossover and case-timecontrol designs. Epidemiology 1996;7:231-9

37. Cooper BJ, Bacal E, Patterson R. Allergic angiitis and granulomatosis. Prolonged remission induced by combined prednisone-azathioprine therapy. Arch Intern Med 1978;138:367-71.

38. Haas C, Géneau C, Odinot JM, et al. Allergic angiitis with granulomatosis: ChurgStrauss syndrome. Retrospective study of 16 cases (French). Ann Méd Interne (Paris) 1991;142:335-42.

39. Aronson JK, Ferner RE. Clarification of terminology in drug safety. Drug Saf 2005:28:851-70.

40. Bili A, Condemi JJ, Bottone SM, et al. Seven cases of complete and incomplete forms of Churg-Strauss syndrome not related to leukotriene receptor antagonists. J Allergy Clin Immunol 1999;104:1060-5.

41. Lobel H, Machtey I, Eldror MY. Pulmonary infiltrates with eosinophilia in an asthmatic patient treated with disodium cromoglycate. Lancet 1972;2:1032.

42. Wong CS, Cooper S, Britton JR, et al. Steroid sparing effect of nedocromil sodium in asthmatic patients on high doses of inhaled steroids. Clin Exp Allergy 1993;23:370-6. 